\title{
Desejo, renúncia, ascese e salvação em Schopenhauer
}

\author{
Desire, renunciation, asceticism and salvation in Schopenhauer
}

\author{
Renato Nunes Bittencourt \\ Doutor em Filosofia pelo PPGF-UFRJ \\ Professor de Filosofia da FACC-UFRJ \\ E-mail: renatonunesbittencourt@gmail.com
}

\begin{abstract}
Resumo: $\mathrm{O}$ artigo aborda o caráter filosóficamente revolucionário do pensamento de Schopenhauer acerca do processo ontológico da negação da Vontade, representado materialmente na era moderna pela ruptura com a ordem materialista da sociedade de consumo, produtora de ilusões de satisfação e gozo para seus sectários. Tal circunstância faz de Schopenhauer uma voz dissonante aos apelos do materialismo vulgar do regime capitalista por dissecar filosoficamente as bases psicológicas que o sustentam, a exaltação dos desejos jámais realizados convenientemente.
\end{abstract}

Palavras-chave: Desejo; Sofrimento; Renúncia; Ascese; Vontade.
Abstract: The article discusses the character thought of Schopenhauer's revolutionary philosophically about the ontological process of negation of the will, represented materially in the modern era by the break with the materialistic consumer society order, delusions of satisfaction and enjoyment to their sectarian. Such circumstance makes Schopenhauer a dissonant voice to the calls of the vulgar materiallism of capitalist regime by the vulgar materiallism of capitalist regime by dissecting the psychological bases that philosophically support, the exaltation of wishes never performed properly.

Keywords: Desire; Suffering; Resignation; Asceticism; Will. 


\section{Introdução}

obra de Schopenhauer desponta extemporaneamente no cenário do
pensamento europeu em um período histórico talvez axiologicamente
incompatível com a intensidade de sua filosofia. Nos albores do Oitocentismo, marcado seja pela apologia da técnica como emancipadora do homem perante suas limitações naturais, como também pela crença no progresso contínuo nas ciências que libertaria a estrutura social de toda contingência, assim como pela paulatina libertação do dogmatismo eclesiástico e na dissolução progressiva da antiga ordenação de mundo feudal para o mundo industrial/urbano, a filosofia de Schopenhauer não se deixa influenciar axiologicamente por tais fatores, que em nada modificam a essência do universo, um ciclo perpétuo de nascimento e morte de suas forças vitais. 0 otimismo moderno no avanço sem limites da condição humana mediada pela técnica e suas realizações rumo ao materialmente melhor não seduziram o gênio schopenhaueriano, e os acontecimentos vindouros da humanidade, para além das dicotomias culturais entre Ocidente/Oriente, provaram o quão certa estava a sabedoria de nosso filósofo. Nessas condições, imputar a Schopenhauer a pecha de representante do reacionarismo burguês é uma falácia estúpida e axiologicamente improcedente, pois de modo algum o filósofo coadunou com os paradigmas medíocres dos filisteus e seus asseclas, enaltecendo a vida de luxo de uma sociedade moralmente embotada e decadente, desprovida de qualquer senso de justiça e de responsabilidade para com o sofrimento dos viventes. Jamais a obra de Schopenhauer chancelou o ethos tacanho dos materialistas vulgares, cuja única fruição se encerra na satisfação dos apetites do baixo ventre e das mesquinharias da mundanidade prosaica. Eis assim alguns fatores que concedem a Schopenhauer um patamar especial no cenário da filosofia moderna, pois, acima de tudo, nosso celebrado autor jamais chancelou o status quo, antes sendo uma das suas antíteses mais impressionantes.

No decorrer desse artigo veremos alguns aspectos fundamentais dessa crítica ao modelo de organização civilizacional que impediu ao ser humano desvelar o verdadeiro sentido oculto do mundo, mergulhando-o no mar das ilusões potencializado pela afluência da sociedade de consumo. 


\section{Renúncia, ascese e salvação}

A ontologia de Schopenhauer se configura pela compreensão terrificante de que os desejos humanos fundamentam as ações do indivíduo comum, que vive em função dos esforços cotidianos para satisfazer seus apetites tirânicos. A racionalidade pode moderar o ímpeto das paixões, mas não encontra forças de contenção que sejam satisfatórias em tal empreendimento. Para Schopenhauer,

Querer e esforçar-se são sua única essência, comparável a uma sede
insaciável. A base de todo querer, entretanto, é necessidade, carência,
logo, sofrimento, ao qual consequentemente o homem está destinado
originalmente pelo seu ser. Quando lhe falta o objeto do querer, retirado
pela rápida e fácil satisfação, assaltam-lhe vazio e tédio aterradores, isto
é, seu ser e sua existência mesma se lhe tornam um fardo insuportável.
Sua vida, portanto, oscila como um pêndulo, para aqui e para acolá,
entre a dor e o tédio, as quais em realidade são seus componentes
básicos. Isso também foi expresso de maneira bastante singular quando
se disse que, após o homem ter posto todo sofrimento e tormento no
Inferno, nada restou para o Céu senão o tédio ${ }^{1}$.

As aspirações humanas são ilimitadas, mas a capacidade de realizá-las é limitada; logo, sempre desponta o mal-estar desse descompasso, ainda mais se levarmos em consideração que, em decorrência da fragmentação da Vontade em sua individuação pelas categorias do espaço e do tempo, o embate pela conservação da existência entre as figurações individuais se torna a tônica da vida. 0 desejo é a raiz de todo ímpeto humano no seu processo constante de afirmação de si em detrimento dos outros, motivando não raro a realização das ações mais violentas e extremas para concretizar as inclinações individuais, daí decorrendo a inevitável comparação com o pensamento hobbesiano acerca do pretenso estado de natureza, na terrível "guerra que é de todos os homens contra todos os homens"2.

O egoísmo se contrapõe ao princípio ético e ontológico da compaixão, que permite justamente ao sujeito compreender-se como imediatamente unificado ao ser do outro, para além de todas as aparências. Contudo, essa fusão como que mística do eu com o outro é um processo que independe da educação e do querer, sendo antes uma revelação extra-racional manifestada na consciência do sujeito, liberto das ilusões

\footnotetext{
${ }^{1}$ SCHOPENHAUER, A. WWV/MVR, I, § 57, p. 401-402.

${ }^{2}$ HOBBES, T. Leviatã, p. 109.
} 
fenomênicas que promovem sua pretensa separação ontológica entre os demais viventes. Não há garantias para a efetivação desse processo extraordinário, não obstante ela poder ocorrer em qualquer tipo humano, independentemente da sua instrução/formação. Esse é o grande mistério da ética. Conforme argumenta Schopenhauer,

Toda boa ação totalmente pura, toda ajuda verdadeiramente desinteressada que, como tal, tem exclusivamente por motivo a necessidade de outrem, é, quando pesquisada até o seu último fundamento, uma ação misteriosa, uma mística prática, contanto que surja por fim do mesmo conhecimento que constitui a essência de toda mística propriamente dita e não possa ser explicável com verdade de nenhuma outra maneira ${ }^{3}$.

Para aquele que compreende intuitivamente a ausência de sentido na ordem mundana da vida e suas tolas fantasias por sucesso e reconhecimento, a instância impulsionadora do querer é razoavelmente atenuada, gerando assim a renúncia ao agir, inclusive a toda pretensão heroica de transformação da ordem politica do mundo, comandada por tiranos e por ladrões ${ }^{4}$. Daí a importância ontológica da tragédia tal como atribuída por Schopenhauer, não como arte dedicada ao entretenimento do sujeito ávido por passatempo, por emoções intensas para depois retornar ao seu estado de conforto moral perante todas as dores do mundo. A tragédia revela em sua verdade fundamental que "os heróis não expiam os seus pecados individuais, mas o pecado original, isto é, a culpa da existência mesma"5. 0 sentido filosófico da tragédia consiste em demonstrar a purificação espiritual do indivíduo que renuncia ao agir por reconhecer o caráter inevitavelmente degradado da sociedade humana6.

\footnotetext{
3 SCHOPENHAUER, A. M, § 22, p. 221.

4 "Observamos não apenas como cada procura arrancar do outro o que ele mesmo quer ter, mas inclusive como alguém, em vista de aumentar seu bem-estar por acréscimo insignificante, chega ao ponto de destruir toda a felicidade ou a vida de outrem. Eis aí a suprema expressão do egoísmo, cujos fenômenos, nesse aspecto, são superados apenas por aqueles de pura maldade, que procura, indiferentemente e sem benefício pessoal algum, a injúria e a dor alheia" (SCHOPENHAUER, A. WWV/MVR, I, § 60, p. 427-428).

5 SCHOPENHAUER, A. WWV/MVR, I, § 51, p. 294.

6 Para enriquecimento do debate teórico sobre essa questão é de grande valia fazermos a comparação textual com a obra do dramaturgo espanhol Pedro Calderón de la Barca (1600-1681), A Vida é Sonho, de grande influência sobre a concepção schopenhaueriana acerca da culpa trágica, mediante a fala lamentosa do Príncipe Segismundo, se expressa o grande desgosto pela existência: “Ai, mísero de mim! Ai, infeliz! /Descobrir, oh Deus pretendo,/ já que me tratas assim/ que delito cometi / fatal, contra ti, nascendo./ Mas eu nasci, e compreendo que o crime foi cometido/pois o delito maior / do homem é ter nascido. / Só queria saber / se em algo mais te ofendi / pra me castigares mais./ Não nasceram os demais?/ Então, se os outros nasceram / que privilégios tiveram / que eu não tive jamais?" (Primeira Jornada).

Desejo, renúncia, ascese e salvação em Schopenhauer
} 
A perspectiva de Schopenhauer não é um mero conformismo ético, pois a vitória da injustiça individual perpetrada pelo indivíduo egoísta é ilusória, uma vez que todo o sucesso na ordem material do mundo se esvai com a própria degradação orgânica da vida individual, suprimida pela morte física. Logo, o triunfo de toda tirania, não obstante ofender a consciência ética de todo indivíduo que é imbuído interiormente pelo senso de justiça, é apenas a face aparente do mal mundano, que não afeta jamais a imutabilidade do Uno Originário, por isso toda tentativa de mudança da ordem social seria, ao fim e ao cabo, fadada ao fracasso. A morte encerra todos os projetos, todas as bondades e todas as vilanias. Nessa concepção, poder-se-ia dizer que tal discurso fatalista favorece a perpetuação do status quo, já que os oprimidos se resignam perante a violência dos seus opressores. Contudo, a filosofia schopenhaueriana não postula a existência de uma justiça divina que no fim dos tempos julgará os bons e os maus, dando aos primeiros, os cordeiros da virtude, a salvação espiritual, e aos segundos a danação eterna, circunstância que serve de consolo moral para as almas oprimidas na vida concreta. Após a morte física toda a configuração existencial se dissipa, e nada espera pelo sujeito, apenas a inevitabilidade do não-ser. A verdadeira renúncia ao Mal não ocorre pelo medo decorrente da consciência da morte ou pela crença na punição divina, mas pela intuição da identidade ontológica de todos os seres, o sofrimento imposto pelo malvado ao fraco também acaba por afetar, em verdade, o agressor, pois ambos constituem a mesma unidade vital:

0 atormentador e o atormentado são um: o primeiro erra ao acreditar que não participa do tormento, o segundo a acreditar que não participa da culpa. Se os olhos dos dois fossem abertos, quem inflige o sofrimento reconheceria que vive em tudo aquilo que no vasto mundo padece tormento e, se dotado de faculdade de razão, ponderaria em vão por que foi chamado à existência para um tão grande sofrimento, cuja culpa não entende; o atormentado notaria que todo mal que é praticado no mundo, ou que já o foi, também procede daquela Vontade constituinte de sua própria essência, que aparece nele, reconhecendo mediante esta aparência e a sua afirmação que ele mesmo assumiu todo sofrimento procedente da Vontade, e isso com justiça, suportando-as enquanto ele é essa Vontade?

Para Schopenhauer, a fruição do belo na arte promove a paulatina supressão do 
desejo humano, pois a consciência individual se emancipa provisoriamente do querer, e assim a mente humana é capaz de contemplar por um instante de suspensão do tempo ordinário as verdades imutáveis das Ideias, experiência de elevação cognitiva que apazigua o ânimo humano e dissolve a efervescência das inclinações:

Aquilo que se poderia nomear o lado mais belo e a pura alegria da vida, precisamente porque nos arranca da existência real e nos transforma em espectadores desinteressados diante dela, é o puro conhecimento que permanece alheio a todo querer; é a fruição do belo, a alegria autêntica na arte ${ }^{8}$.

Dentre as belas-artes, conforme a hierarquização schopenhaueriana, é a tragédia aquela que exerce maior efeito moral sobre a consciência individual, em especial a tragédia cristã, seja em seus motivos cristãos, ou aquela elaborada conforme seus preceitos morais, enraizados na negação da vontade de viver, na denúncia do Mal moral latente na ordem mundana, atuando então no contemplador como um exercício de renúncia ao agir. No sofrimento do herói que tanto aspirou virtuosamente pela concretização da justiça e que venceu provisoriamente as adversidades com as quais se defrontava até sucumbir definitivamente perante as forças tirânicas que dominam o mundo concreto, vemos que a vida é um negócio que não vale o investimento, e que o próprio pecado da individuação é punido.

Nesses termos, a tragédia atua não como uma catarse que ao fim purifica a alma humana liberando-a do temor e da piedade tal como Aristóteles propunha em sua Poética, mas sim como um calmante da vontade individual, incutindo no sujeito a resignação e renúncia ao agir. Sempre esse mote deve ser lembrado: a vitória da maldade é apenas aparente, afeta apenas a dimensão dos fenômenos, jamais a essência do mundo, ou seja, a Vontade, logo, o ser real não é prejudicado pela iniquidade dos indivíduos iludidos pelo Véu de Maya que acreditam obter ganho real com seus crimes. Dessa compreensão metafísica aflora no sujeito liberto do querer a noção de que não adianta qualquer pretensão de mudança em uma figuração mundana intrinsecamente ruim. A renúncia proposta por Schopenhauer não significa impotência de agir, motivada pela impossibilidade de exercer o querer; pelo contrário, é sinal de uma poderosa capacidade do sujeito efetivamente liberto de toda sorte de inclinações, suprimir qualquer

${ }^{8}$ SCHOPENHAUER, A. WWV/MVR, I, § 57, p. 404.

Desejo, renúncia, ascese e salvação em Schopenhauer 
possibilidade de afirmar as condições da vida. Por conseguinte, esse indivíduo que renúncia é também um herói, não pela gloriosa afirmação da existência, mas pela negação definitiva da mesma:

Porque todo sofrimento é uma mortificação e um chamado à resignação, possui potencialmente uma força santificadora; e isso explica o fato de grandes desgraças e dores profundas já em si mesmas inspirarem certo respeito [...] Só quando o sofrimento assume a forma do simples e puro conhecer, e este, como quietivo da Vontade, produz a resignação, é que se acha o caminho da redenção, sendo pois o sofrimento digno de reverência9.

A contemplação estética do belo nas artes e em especial o efeito lenitivo da Vontade proporcionado pela cena trágica, conforme apresentado por Schopenhauer, não garantem ao sujeito que compreendeu o caráter terrífico da existência uma vitória mais intensa sobre os tormentos do querer, atuando talvez como um calmante temporário que, após seu efeito apaziguador do ânimo humano, torna a manifestar sua força opressiva sobre o mesmo. Por conseguinte, a contemplação estética por si só não é o suficiente para a redenção do sujeito do querer, dependendo assim da prática ética. Todavia, a demonstração estética do fundamento péssimo do mundo é o anteparo para a organização da ética pautada na renúncia e na ascese absoluta mediante a negação de si e de seu instrumento mais potente, o corpo prenhe de desejos.

É em sua Metafísica da Ética que Schopenhauer apresentará um viés para a negação absoluta da vontade de viver, solução para a supressão do grande mal estar existencial da vida regida pela adequação constante aos desejos, majoritariamente insatisfeitos. Quando ocorre a satisfação, inevitavelmente provisória, desponta o tédio, e assim a roda do querer torna a girar, até a extinção da vida individual pelo fenômeno da morte. A luta pela satisfação é constante, mas essa satisfação é sempre momentânea, e a compreensão desse mecanismo muitas vezes passa despercebida na vida mediana e serve de estímulo sôfrego para a manutenção da existência. Segundo Schopenhauer,

Todo querer nasce de uma necessidade, portanto de uma carência, logo, de um sofrimento. A satisfação põe um fim ao sofrimento; todavia, contra cada desejo satisfeito permanecem pelo menos dez que não o são. Ademais a nossa cobiça dura muito, as nossas exigências não conhecem limites; a satisfação, ao contrário, é breve e módica. Mesmo a

${ }^{9}$ SCHOPENHAUER, A. WWV/MVR, I, § 68, p. 459. 
satisfação final é apenas aparente: o desejo satisfeito logo dá lugar a um novo: aquele é um erro conhecido, este um erro ainda desconhecido. Objeto algum alcançado pelo querer pode fornecer uma satisfação duradoura, sem fim, mas ela se assemelha sempre apenas a uma esmola atirada ao mendigo, que torna sua vida menos miserável hoje para prolongar seu sofrimento amanhã ${ }^{10}$.

O reconhecimento do caráter contraditório da Vontade manifestada na dimensão individual, que luta contra si mesma, altera a polarização desse princípio. Ao invés de se autoafirmar, a Vontade passa a negar a si mesma, primeiramente mediante a compreensão da unidade fundamental de todos os viventes proporcionada pela compaixão, abolindo-se assim as fronteiras entre o sujeito e o mundo. Nas suas duas virtudes fundamentais, justiça e caridade, o egoísmo é suprimido, respeitando-se a pessoa do outro e fazendo-se ações extraordinárias para a efetivação do seu bem material e moral. Contudo, nessa dimensão ética, as disposições de ação são relacionais, faz-se justiça para com o outro, faz-se caridade para com o outro, atenuando razoavelmente o grande mal-estar do mundo dominado pelo egoísmo e pela maldade. Porém, há ainda uma grande instância a ser vencida, o próprio eu, e seus ardorosos apelos por satisfação desiderativa, cujos efeitos práticos são inevitavelmente terríveis. Nesse momento ocorre a etapa mor do processo de negação da Vontade, através da ascese, que se manifesta das formas mais intensas de modo a suprimir definitivamente a vontade individualizada que faz do eu um ser miserável em busca constante por adições. 0 jejum, a maceração do corpo, a abdicação do prazer sensível são exemplos de procedimentos ascéticos que dissolvem os apelos da carne; o corpo é mantido apenas no quantum de energia necessário para sua sobrevivência.

Tal homem que, após muitas lutas amargas contra a própria natureza, finalmente a ultrapassou por inteiro, subsiste somente como puro ser cognoscente, espelho límpido do mundo. Nada mais o pode angustiar ou excitar, pois ele cortou todos os milhares de laços volitivos que o amarravam ao mundo, e que nos jogam daqui para acolá, em constante dor, nas mãos da cobiça, do medo, da inveja, da cólera11.

Os iogues e santos católicos, assim como muitos filósofos pagãos cujas vidas foram exemplo de frugalidade e desapego material, são testemunho em suas vidas dessa

10 SCHOPENHAUER, A. WWV/MVR, I, § 38, p. 266.

11 SCHOPENHAUER, A, WWV/MVR, I, § 68, p. 495.

Desejo, renúncia, ascese e salvação em Schopenhauer 
disciplina ascética, considerando que a ordem do mundo é pura vaidade, ilusão. Todas as ditas novidades propagadas a cada dia nos mercados não são capazes de seduzir a consciência do asceta, pois o ritmo de obsolescência das coisas que dá lugar ao sempre novo é incessante e incontrolável, de modo que o apego a tais fugacidades é fonte de desespero, frustração, infelicidade. Schopenhauer argumenta que

Quando às vezes em meio aos nossos duros sofrimentos sentidos, ou devido ao conhecimento vivo do sofrimento alheio e ainda envoltos pelo Véu de Maya o conhecimento da nulidade e amargura da vida se aproxima de nós e gostaríamos de renunciar decisivamente para sempre ao espinho de suas cobiças e fechar a entrada a qualquer sofrimento, purificar-nos e santificar-nos, logo a ilusão do fenômeno nos encanta de novo e seus motivos colocam mais uma vez a vontade em movimento. Não podemos nos libertar. As promessas da esperança, as adulações do tempo presente, a doçura dos gozos, o bem-estar que fazem a nossa pessoa partícipe da penúria de um mundo sofrente sob o império do acaso e do erro atraem-nos novamente ao mundo e reforçam os nossos laços de ligação com ele ${ }^{12}$.

A verdadeira ascese nega o mundo, de modo algum coaduna com a sua manutenção. Por conseguinte, a ascese protestante tal como interpretada competentemente por Max Weber seria a perpetuação de Maya, pois apesar do devoto negar o prazer carnal em suas ações laborais fundamentadas no ethos religioso, o resultado de sua ação beneficia a ordem material da sociedade e suas criações técnicas ${ }^{13}$. A verdadeira ascese, compreendendo o caráter sem sentido do mundo, nega-o, por isso resulta na inação, na renúncia ao agir, favorecendo assim um afastamento radical da ordem mundana. 0 ethos protestante apenas reformou as bases corrompidas do establishment cristão enquanto instituição política, mas revelou-se incapaz de vivenciar plenamente o autentico espírito crístico original, pautado no consistente nãoreconhecimento da ordem do mundo, das suas riquezas, dos seus valores.

De maneira alguma a perspectiva schopenhaueriana poderia ser aplicada negativamente em um viés político, pois o filósofo justamente considera que toda tentativa de mudança na ordem do mundo não altera a essência metafísica do mesmo,

12 SCHOPENHAUER, A. WWV/MVR, I, § 68, p. 482.

13 "Ora, a conduta de vida monástica é encarada não só como evidentemente sem valor para a justificação perante Deus, mas também como produto de uma egoística falta de amor que se esquiva aos deveres do mundo [...] 0 feito propriamente dito da Reforma consistiu simplesmente em ter já no primeiro momento inflado fortemente, em contraste com a concepção católica, a ênfase moral e o prêmio religioso para o trabalho intramundano no quadro das profissões" (WEBER, M. A ética protestante e o "espírito" do capitalismo; p. 73; p. 75). 
mas apenas os seus fenômenos. 0 que é possível na ordem prática é apenas o controle do Estado como grande coleira social, impedindo o assassinato mútuo dos indivíduos e sua inerente barbárie, pois

(...) 0 Estado, intentando o bem-estar, não foi de modo algum instituído contra o egoísmo, mas pura e simplesmente contra as consequências desvantajosas dele, oriundas da pluralidade dos indivíduos egoístas, reciprocamente afetados e perturbados em seu bem-estar ${ }^{14}$.

$\mathrm{Na}$ ascese, o sujeito paulatinamente se divorcia da vontade, suportando todo sofrimento psicofísico, toda privação material, com paciência, abnegação, tranquilidade de ânimo, encontrando nesse exercício de superação de si mesmo não a tristeza comum do indivíduo que, destituído dos meios de gozar as benesses da vida, se deprime por sua carência, mas a felicidade, pois reconhece que todos os apelos sensíveis são caprichosos e fugazes e não são merecedores de maiores considerações:

Sentimos que toda satisfação de nossos desejos advinda do mundo assemelha-se à esmola que mantém hoje o mendigo vivo, porém prolonga amanhã sua fome. A resignação, ao contrário, assemelha-se à fortuna herdade: livra o herdeiro para sempre de todas as preocupações ${ }^{15}$.

Ao contrário do que pensa a humanidade ordinária que postula a busca de riqueza para satisfazer os desejos que despontam continuamente como a finalidade superior da existência, a genuína consciência ascética pressupõe que a sabedoria por excelência é matar a fonte dos desejos, tornando assim o corpo insensível aos imperativos carnais. Nesse ponto podemos remeter a problematização schopenhaueriana a um dos temas fundamentais da filosofia platônica na sua orientação ascética: a ideia da atividade filosófica como uma preparação para a morte, pois se configura como exercício racional de instrumento de apaziguamento da vitalidade do corpo, por meio da luminosidade racional da reflexão filosófica, o ser humano adquiriria o seu mais completo autodomínio, tornando-se efetivamente livre das contradições das paixões e dos grilhões da sensibilidade ${ }^{16}$. A contemplação desinteressada das Ideias

${ }^{14}$ SCHOPENHAUER, A. WWV/MVR, I, § 62, p. 401.

15 SCHOPENHAUER, A. WWV/MVR, I, § 68, p. 494.

${ }^{16}$ Sobre o Melete Thanatou e a sua suma importância para o desenvolvimento pleno do potencial filosófico, Cf. PLATÃo. Fédon, 82d - 83b. 
retira 0 ardor da vontade.

A imagem tradicional do filósofo é a do indivíduo emancipado da ordem mundana das coisas, concentrado apenas nas questões ontológicas da existência e da busca pelo conhecimento. Por isso se associou tradicionalmente o ofício filosófico ao estado de solidão, circunstância imputada como propicia para a dedicação cabal ao plano do saber. Quem vislumbra se dedicar intensamente ao plano intelectual não pode jamais ficar submisso perante as contingências prosaicas da vida corriqueira, sob o risco de não realizar plenamente nenhuma das instâncias: tornar-se-á um intelectual limitado ou um homem de família avoado ${ }^{17}$. Obviamente que podemos encontrar na história da cultura casos muito bem-sucedidos de intelectuais que desenvolveram ótima conciliação entre suas atividades criadoras e as demandas familiares, e tal situação é louvável. Mas não podemos jamais depreciar os intelectuais que preferiram se dedicar hegemonicamente ao trabalho do pensamento e suas inerentes investigações pela ampliação do saber, renunciando inclusive ao amor conjugal para que tivessem mais concentração em tal empreitada. Isso se configura como um ascetismo consciente, que favorece o fortalecimento do foco da inteligência criadora para as causas imputadas como dotadas de verdadeiro significado e valor.

Já para aqueles que são incapazes de viver na pureza espiritual, a própria existência é já um infortúnio, ainda que aparentemente seja marcada pelo bem-estar material. Para essa chusma humana, nem as realizações intelectuais nem a felicidade legítima da vida familiar conseguem elevar seu nível de consciência para alguma instância acima de sua própria condição pessoal, culminando em seu naufrágio existencial como um sinal do vazio da vida sem qualquer ímpeto de autorrealização. Para o modo de existência decadente e axiologicamente medíocre, a boa vida consiste apenas em se desfrutar das benesses materiais, das viagens turísticas e dos prazeres sensíveis imediatos. Essa massa humana demonstra avidez em conhecer o mundo, mas de que adianta conhecer o mundo sem que primeiramente se conheça a si mesmo? Esse é o Inferno moral dos submissos ao hedonismo desenfreado da sociedade de consumo. Conforme Schopenhauer,

Toda satisfação, ou aquilo que comumente se chama felicidade, é própria e essencialmente falando apenas negativa, jamais positiva. Não

\footnotetext{
17 Nietzsche, na Genealogia da Moral, p. 89, afirma que "o filósofo tem horror ao casamento, e a tudo o que a ele poderia conduzir" e que "um filósofo casado é coisa de comédias". 
se trata de um contentamento que chega a nós originalmente, por si mesmo, mas sempre tem de ser a satisfação de um desejo; pois o desejo, isto é, a carência, é a condição prévia de todo prazer. Com a satisfação, entretanto, finda o desejo, por consequência o prazer. Eis por que a satisfação ou o contentamento nada é senão a liberação de uma dor, de uma necessidade, pois a esta pertence não apenas cada sofrimento real, manifesto, mas também cada desejo, cuja inoportunidade perturba nossa paz, sim, até mesmo o mortífero tédio que torna a nossa existência um fardo ${ }^{18}$.

Com efeito, a mentalidade idiotizada da civilização burguesa compreende a experiência da felicidade como a satisfação razoável dos seus desejos privados, fomentados artificialmente, em sua grande parte, pela indústria do consumo, grande produtora de ilusões da modernidade. Orbitando tal como uma mosca sobre as coisas disponíveis no grande mercado capitalista, o sujeito seduzido pelas ilusões monetaristas acredita poder adquirir tudo que se encontra ao seu alcance, mas ao fim e ao cabo reconhece amargamente que não pode obter a tão ansiada felicidade, assim como a vitória sobre o tédio e, tanto pior, sobre a condição derradeira que tanto assola o homem afetado pelas paixões reativas: a morte.

A civilização ocidental concedeu sentido negativo e pejorativo ao Nada, imputando-o como o não-ser, a ausência de atributos, e tanto pior, mediante uma concepção moralista, associou-lhe ao âmbito do Mal. Isso evidencia a incapacidade do pensamento binário do mundo ocidental compreender o caráter radical do Nada em sua relação com a negação da Vontade, o que resulta no aniquilamento da própria fonte de ilusões da dimensão fenomênica da vida e suas criações que ao fim e ao cabo escravizam o próprio ser humano nas suas cadeias inextrincáveis. $\mathrm{Na}$ dimensão concreta a exemplificação dessa negação da Vontade como ruptura radical com a ordem mundana ocorre na adesão ao modo de vida pobre, o ascetismo monástico que nasce do reconhecimento que a afluência dos bens materiais é um genuíno ouro de tolo sedutor das consciências afoitas pela satisfação dos seus desejos sensíveis. No seio de tanta abundância material, a negação voluntária da mesma pode ser considerada como um ato heroico, pois a batalha pela vitória é travada na própria interioridade do indivíduo que aniquila seu ardor pessoal pela posse e pelo gozo. $\mathrm{Na}$ dimensão exotérica da religiosidade, a grande promessa compensatória aos ascetas que renunciam ao prazer sensório em prol da pureza espiritual é o mundo celestial, o Paraíso. Contudo, para os 
indivíduos que desmistificaram todas as formas de ilusões que são produzidas em suas diversas categorizações ideológicas pela mentalidade humana, não há qualquer prêmio para a negação da Vontade, apenas o Nada. Essa é assim a culminação do projeto trágico de Schopenhauer, a vitória sobre o querer não se dá na fuga do mundo rumo ao suprassensível, mas na sua negação na vida mesma, com todas as suas contradições e apelos heteróclitos.

\section{Considerações Finais}

Podemos considerar que a obra de Schopenhauer fornece subsídios para a crítica da moral capitalista e suas interfaces na dita sociedade de consumo mediante a apresentação da ontologia desiderativa do homem e seu inerente apego aos bens materiais e usufruto desenfreado dos mesmos, pois na realidade material vigente, o que importa é a disposição para ter, jamais a capacidade de ser, de fruir placidamente a beleza da natureza e da arte, assim como de não se apegar doentiamente aos benefícios sensíveis das coisas. Por conseguinte, considerá-lo como um ideólogo burguês é um erro crasso, pois sua doutrina se dissocia de todas as falsidades e formalidades que regem o ethos burguês e seu materialismo filisteu.

No plano da ética, Schopenhauer é inovador ao se contrapor à barbárie escravista cometida contra os negros em uma época que grandes políticos e mestres da humanidade, por preconceito e/ou conveniência, defendiam a escravidão e/ou a superioridade dos brancos sobre os demais. Schopenhauer integra a consideração ética pelos animais sem a pieguice inócua dos cidadãos de bem edulcorados, mas como consequência necessária de sua doutrina da compaixão. Com efeito, ao reconhecer a unidade fundamental que perpassa todos os viventes, o sujeito compassivo não estabelece mais distinções ontológicas entre o eu e o outro, de modo que toda violência contra um ser vivo significa uma violência contra si mesmo.

Cabe ainda ressaltar que Schopenhauer foi um dos primeiros pensadores ocidentais a beber nas fontes da antiquíssima sabedoria oriental sem dela fazer um uso estereotipado, eivado de exotismo tal como um desbravador deslumbrado perante o novo. Jocosamente poderíamos nos indagar o que Schopenhauer teria a dizer sobre a sôfrega demanda turística do homem moderno submetido aos apelos comerciais por experiências sempre insólitas para tonificar sua existência embotada pela perda de 
sensibilidade mediante absorção de tantos estímulos conflitantes. O filósofo alemão apresenta um estofo ontológico para absorver conhecimento primordial da cultura védica e do Budismo, fazendo assim jus a tais concepções de mundo. Compreendendo que a marcha do conhecimento nasceu do Oriente e alcançou posteriormente o Ocidente, Schopenhauer desfere golpes poderosíssimos contra um dos maiores problemas étnicos da era moderna, o eurocentrismo, cuja ideologia legitimou tantos crimes contra a humanidade, crimes travestidos pelos bem aceitos conceitos de progresso, razão, desenvolvimento industrial. Não podemos encontrar na sua doutrina efetivos elementos revolucionários? Contudo, deixaremos essas questões para abordagens posteriores, pois jamais um escrito conseguirá dar conta da diversidade de ideias insólitas de tão profundo pensador.

\section{Referências bibliográficas}

ARISTÓTELES. Poética. Trad. de Eudoro de Souza. Lisboa: INCM, 1992.

CALDERÓN DE LA BARCA, Pedro. A Vida é Sonho. Trad. de Renata Pallottini. São Paulo: Hedra, 2007.

HOBBES, Thomas. Leviatã ou Matéria, Forma e Poder de um Estado Eclesiástico e Civil. In Vol. Hobbes, Col. Os Pensadores. Trad. de João Paulo Monteiro e Maria Beatriz N. da Silva. São Paulo: Nova Cultural, 1997.

NIETZSCHE, Friedrich. Genealogia da Moral: uma polêmica. Trad. de Paulo César de Souza. São Paulo: Companhia das Letras, 2009.

PLATÃo. Fédon. Trad. de Maria Tereza Schiappa de Azevedo. Brasília: Editora da UnB, 2000.

SCHOPENHAUER, Arthur. O Mundo como Vontade e como Representação, Tomo I. Trad. de Jair Barboza. São Paulo: Ed. UNESP, 2005.

- Sobre o Fundamento da Moral. Trad. Maria Lucia Mello e Oliveira Cacciola. São Paulo: Martins Fontes, 2001.

WEBER, Max. A ética protestante e o "espírito" do capitalismo. Trad. de José Marcos Mariani de Macedo. São Paulo: Companhia das Letras, 2004. 